\title{
Terapia Computacional: uma vivência voltada para o tratamento de pacientes com transtornos psíquicos mediado pela ferramenta Scratch
}

\author{
Lucas Borges Leal ${ }^{1}$, Keylla Maria de Sá Urtiga Aita ${ }^{1}$, Aline Montenegro \\ Leal Silva ${ }^{1}$ \\ ${ }^{1}$ Centro de Educação Aberta e à Distância - Universidade Federal do Piauí \\ (UFPI) - Rua Olavo Bilac, 1148, 64001-280, Teresina - PI- Brasil \\ lucasboorges13@gmail.com, keyllaurtiga@ufpi.edu.br, \\ alineleal5eyahoo.com.br
}

\begin{abstract}
The use of Information and Communication Technologies (ICTs) has been causing significant changes in the ways of working, teaching and learning, social skills and inclusion of minorities. Thus, this article presents experiences of psychiatric patients at the Psychosocial Care Center (CAPS) in the city of Inhuma do Piaui with the use of the Scratch tool, with regard to the promotion of cognitive skills in the artisanal sphere. The use of the Scratch tool was mediated by the institution's artisan who interacted directly with the patients. The objective of the work is to promote the interference of digital resources in the space of therapies, as a way to digitally include this portion of the population.
\end{abstract}

Resumo. O uso das Tecnologias da Informação e Comunicação (TICs) vêm provocando significativas mudanças quanto aos modos de trabalho, ensinoaprendizagem, habilidades sociais e inclusão de minorias. Deste modo, este artigo apresenta experiências de pacientes psiquiátricos do Centro de Atenção Psicossocial (CAPS) da cidade de Inhuma do Piauí com o uso da ferramenta Scratch, no que tange a promoção das desenvolturas cognitivas no âmbito artesanal. $O$ uso da ferramenta Scratch foi mediado pelo artesão da Instituição que interagiu diretamente com os pacientes. O objetivo do trabalho é promover a interferência de recursos digitais no espaço das terapias, como forma de incluir digitalmente essa parcela da população.

\section{Introdução}

Com o surgimento da reforma psiquiátrica promoveu-se uma evolução excepcional no tratamento psíquico de pacientes portadores de transtornos mentais, como efeito, promoveu-se também o resgate da cidadania dessas pessoas que até então não tinham tratamentos humanitários (Sbardella, 2018). Os primeiros hospitais construídos com o objetivo de afastá-los do convívio da sociedade, nunca priorizaram o zelo no tratamento desses pacientes. Diante disto, a Reforma Psiquiátrica surgiu com o objetivo principal de promover a reinserção dos doentes mentais na sociedade, melhorando suas qualidades de vida por meio de vários programas sociais. Segundo Acioly (2009), um dos pontos positivos da reforma psiquiátrica foi a implantação de serviços de atendimento extra hospitalares, como os Centros de Atenção Psicossociais (CAPS), Centro de Atenção 
Diária (CAD), Hospitais Dias (HDs) e outros.

Com as intervenções das esferas sociais (Federal, Estadual e Municipal), que se apoiaram em movimentos comunitários para materializar a transição de um paradigma assistencial centrado em manicômios para um modelo de atenção comunitário e humanizado, enalteceu-se o processo de inovação da psiquiatria. E após a reforma psiquiátrica ter se alicerçado como política oficial do governo federal, assuntos relacionados à saúde mental tem sido assistidos consideravelmente nas pautas governamentais.

A presença da tecnologia tende a trazer uma socialização imensurável aos Centros de Apoio Psicossocial, teoria na qual se firma nas palavras de BABINSKI (2005): "O CAPS através de suas atividades inovadoras procura o restabelecimento dos laços afetivos fragilizados nos pacientes e familiares". As alterações sociais causados pelo avanço tecnológico podem suscitar uma alternativa coadjuvante às terapias ocupacionais, na perspectiva de que agregando recursos digitais aos procedimentos para o acompanhamento do deficiente mental, pode-se transformar positivamente o espaço terapêutico.

Diante destas circunstâncias, apresenta-se nesta pesquisa as experiências obtidas com o uso da ferramenta Scratch no ambiente terapêutico dos pacientes psiquiátricos do CAPS da cidade de Inhuma, Piaú, onde teve-se por objetivo utilizar mediação tecnológica para potencializar e avaliar a coordenação motora fina, a criatividade intelectual e o nível de visão seletiva de pacientes internos da instituição. O Scratch é uma ferramenta online e gratuita desenvolvida pelo Instituto Tecnológico de Massachussetts para a criação de jogos e animações feitos a partir de comandos pré-programados. Após a experiência, constatou-se que a aplicação desse instrumento computacional associado aos cuidados dos profissionais, despertou interesse e gerou motivação adicional no exercício das atividades terapêuticas promovidas pela instituição.

\section{Saúde mental e inclusão digital}

O impacto das transformações tecnológicas, também chamado "inclusão digital", surgiu como nova tendência fazendo acontecer mutações drásticas nos mais diversos campos sociais revolucionando as relações interpessoais e profissionais, e em amplitude, é nitidamente perceptível o auxílio aos cidadãos na perspectiva de engajamento na sociedade contemporânea.

Existem vários mecanismos digitais que promovem a inclusão de pessoas com transtornos mentais e os resgatam para devolvê-los ao ambiente social, e dentre eles está o Scratch com seus mecanismos que abrangem técnicas das mais simples as mais sofisticadas no ramo da terapia computacional. Segundo Farias et al. (2019):

\footnotetext{
"O Scratch pode ser utilizado para exercitar o pensamento computacional promovendo uma experiência lúdica e motivadora e estimulando a capacidade lógica, cognitiva e criativa."
}

Mesmo com o progresso expressivo de inovação, ainda assim, a reforma psiquiátrica externou relapso em alguns parâmetros sociais, segundo Fortuna e Oliveira (2011), que realizou um reconhecimento introdutório das oficinas midiáticas comunicacionais como atividade psicossocial nos serviços de saúde mental no Brasil, onde se percebeu uma expressividade ampla na quantidade de práticas terapêuticas comunicacionais em serviços de saúde mental através de oficinas de rádio, fotografia, 
web rádio, TV, construção de jornal, sites e produção de vídeos.

Fundamentado nas perspectivas abstratas sobre a inserção da tecnologia na terapia da saúde mental, nota-se conceitos análogos nos procederes dos autores que trabalharam esse tema: inclusão social dos usuários do tratamento da saúde mental mediado pelas tecnologias. Por exemplo, Fulford et al. (2019) atesta o atendimento online, proporcionado pelos softwares, como significativo no tratamento da saúde mental. Fortuna e Oliveira (2011) focam na utilização direta de recursos digitais como auxiliadores do tratamento.

Contudo, a deficiência não é o único motivo que limita os portadores, mas a própria comunidade em que o individuo deficiente está inserido. Esse fator foi um combustível vigoroso para alavancar ainda mais os estudos da pesquisadora Oliveira (2016), que em sua tese de doutorado, realizou um estudo em que buscou analisar na literatura a aplicação de instrumentos tecnológicos para o auxílio em diagnóstico e tomada de decisões médicas em saúde mental, mais especificamente sobre depressão, de modo a justificar a importância e a necessidade de aplicativos e softwares que possam ser usados para melhorar o atendimento de portadores de transtornos depressivos. Os resultados desta análise atenderam as expectações da pesquisadora enfatizando o rastreio de problemas de saúde mental e os potenciais problemas psicossociais como sendo os principais seguimentos obtidos com o estudo, podendo facilitar a comunicação e a tomada de decisão clínica, monitoramento de mudanças ou resposta ao tratamento, possivelmente incrementando a qualidade de vida (Oliveira, 2016).

Quanto ao uso do Scratch, observa-se que a sua versatilidade o torna uma ferramenta com inúmeras competências. A facilidade de interação decorre da clareza de sua interface, e juntamente com a díade de recursos (sonoros e visuais) permitem que este software tenha extensa capilaridade prática. Os trabalhos mencionados a seguir (Tabela 1) são fragmentos de pesquisas recentes que relatam o uso do Scratch e atestam em seus resultados a relevância do uso da ferramenta proporcionando aos usuários a oportunidade de desenvolverem diferentes habilidades.

Tabela 1. Estudos recentes sobre o uso da ferramenta Scratch.

\begin{tabular}{|c|l|}
\hline \multirow{2}{*}{$\begin{array}{c}\text { Farias et al. } \\
\text { (2019) }\end{array}$} & $\begin{array}{l}\text { Concluíram que com o Scratch é possível criar histórias } \\
\text { interativas com personagens e cenários já existentes na } \\
\text { ferramenta. Diante disso, tem-se um estímulo à criatividade e } \\
\text { imaginação. O caráter lúdico do aplicativo provoca um } \\
\text { ensinamento por meio da diversão, tornando o aprendizado mais } \\
\text { fácil. }\end{array}$ \\
\hline $\begin{array}{l}\text { Marinho et al. } \\
\text { (2017) }\end{array}$ & $\begin{array}{l}\text { Segundo os autores, este software ajuda os jovens a pensar de } \\
\text { maneira criativa, refletir de maneira sistemática e trabalhar de } \\
\text { forma colaborativa as habilidades essenciais para a vida no } \\
\text { século XXI. }\end{array}$ \\
\hline
\end{tabular}




\begin{tabular}{|c|l|}
\hline $\begin{array}{c}\text { Leal } \text { et al. } \\
\text { (2019) }\end{array}$ & $\begin{array}{l}\text { Relataram em sua pesquisa que a utilização do Scratch aliado } \\
\text { ao acompanhamento profissional, despertou interesse e gerou } \\
\text { motivação adicional no exercício das atividades terapêuticas } \\
\text { promovidas pela instituição. Portanto, a utilização dessa } \\
\text { ferramenta alcançou o objetivo de incluir e socializar } \\
\text { digitalmente os pacientes psiquiátricos. }\end{array}$ \\
\hline $\begin{array}{c}\text { Santana } \text { et al. } \\
(\mathbf{2 0 1 7 )}\end{array}$ & $\begin{array}{l}\text { Atestaram em sua pesquisa que foi desenvolvida uma } \\
\text { atividade com as crianças com a intenção de familiarizá-los } \\
\text { com os personagens do Scratch Jr, o que estimulou a } \\
\text { criatividade na pintura e criação de histórias para cada } \\
\text { personagem apresentado. }\end{array}$ \\
\hline $\begin{array}{c}\text { Santana, S. e } \\
\text { Oliveira, W. } \\
(\mathbf{2 0 1 9 )}\end{array}$ & $\begin{array}{l}\text { Relataram que nas experiências de uso do Scratch houve } \\
\text { desempenho significativo em aspectos fundamentais, como: } \\
\text { lógica, interatividade com o usuário, representação de dados e } \\
\text { sincronização. }\end{array}$ \\
\hline $\begin{array}{l}\text { Zednik } \text { et al. } \\
(\mathbf{2 0 1 9 )}\end{array}$ & $\begin{array}{l}\text { Afirmaram em sua pesquisa que o programa Scratch pode } \\
\text { auxiliar na deficiência intelectual por permite a criação de } \\
\text { vários recursos que podem estimular ou despertar o interesse } \\
\text { dos usuários. }\end{array}$ \\
\hline
\end{tabular}

No que tange à aplicabilidade direta da Ferramenta Scratch no âmbito das terapias na saúde mental, destaca-se o estudo de Leal et al. (2019) que traz os resultados da pesquisa de campo auxiliada pelo Neuropsicopedagogo do Centro de Atenção Psicossocial (CAPS) da cidade de Inhuma-PI, Adaljerry Ferreira de Sousa. O experimento junto aos pacientes teve como objetivo trabalhar necessidades cognitivas, tais como: coordenação motora, lateralidade, interatividade e visão seletiva. Os resultados indicaram diretamente que: "Com o uso dessa ferramenta (Scratch) pôde-se observar um trabalho intenso da coordenação motora fina que, ao longo de outras sessões de aplicação coordenadas, poderia culminar com um aprimoramento desta função, bem como do desenvolvimento psicomotor, cognitivo e de lateralidade".

\section{Metodologia}

A pesquisa foi realizada no Centro de Atenção Psicossocial (CAPS) do município de Inhuma (Piauí) que atende a uma demanda de aproximadamente 1500 pacientes, entre intensivos, semi-intensivos e não intensivos, que são assistidos pelos diversos profissionais da instituição, sendo eles: psiquiatra, pedagogo, psicólogo, assistente social, educador físico, enfermeiro, técnico de enfermagem e artesão. Os atendimentos são permutados estrategicamente durante os dias úteis semanais, exceto os serviços de enfermagem, que são constantes. Essa estratégia é deliberada pelo psiquiatra que encaminha o paciente para a devida terapia de acordo com o cronograma de realização desta, e apenas o público intensivo tem acesso a todas as terapias do CAPS. Para o público semi-intensivo e não intensivo existe algumas restrições, por exemplo, não tem acesso contínuo as atividades realizadas diariamente no centro.

Metodologicamente, parte-se de uma pesquisa bibliográfica, de caráter documental, que percorreu o protocolo ilustrado na Figura 1. Inicialmente foi realizada a revisão bibliográfica sobre o tema estabelecido buscando trabalhos que correlacionassem os temas: inclusão digital e terapias para pacientes psiquiátricos. A sessão 2 deste 
documento traz a síntese desta etapa e um estudo detalhado da ferramenta Scratch para apropriação do conhecimento necessário à execução do experimento. Nesta etapa, explorou-se as funcionalidades da ferramenta e fez-se simulações em cenários exploratórios distintos para definir qual seria o melhor cenário para potencializar e trabalhar as seguintes capacidades dos pacientes: coordenação motora fina, visão seletiva e a criatividade intelectual. Para isto, percorreu-se a interface à procura dos recursos necessários para trabalhar as variáveis supracitadas e assim promover a melhor experiência do usuário com o software, fornecendo uma prática criativa e estimulante ao paciente. Nesta direção identificou-se que a versatilidade da ferramenta estimulou as necessidades destacadas e, em decorrência disso, lhe foi promovido valor ainda maior à medida que se alcançou novas habilidades através dos níveis de fases ascendentes programadas no software estimulando, a cada passo, a autonomia dos usuários perante a ferramenta.

Figura 1: fluxograma da metodologia. Fonte: o autor, 2020

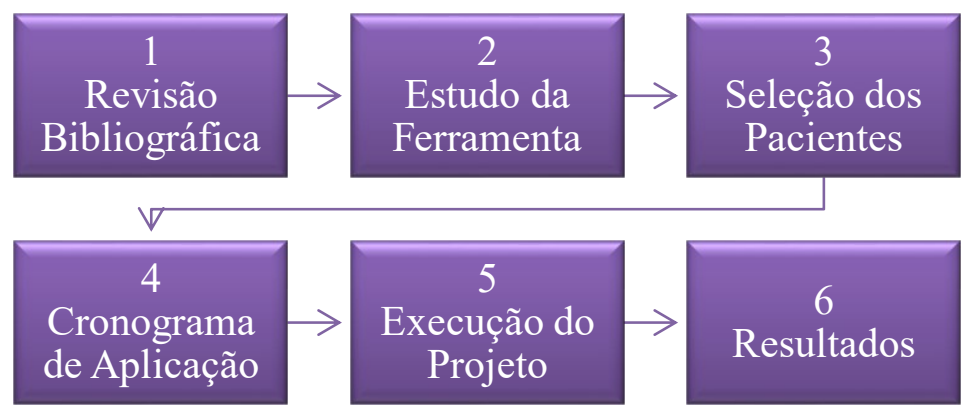

A terceira fase da metodologia foi a seleção dos pacientes, cujo requisito era a escolha dos que tinham condições salubres de interação com a máquina voltado para as suas respectivas necessidades dentre as citadas anteriormente. Nesta seleção, constatouse que apenas quatro, dos dezessete intensivos, estavam habilitados à aplicação da terapia computacional por serem os únicos intensivos com grau de deficiência que os permitisse realizar o experimento. A designação dos pacientes para a execução da terapia se deu pelo psiquiatra, sendo a aplicação monitorada pelo artesão, e ambos apoiados nas instruções da Classificação Internacional de Doenças, edição número 10 (CID 10), um livro que oferece aos profissionais de saúde um código para cada tipo de doença, e no que tange a saúde mental, é titulado a classificação da letra $\mathrm{F}$ para os transtornos mentais existentes.

$\mathrm{Na}$ fase 4 foi definido um cronograma onde se adequou o horário de aplicação prática da terapia de acordo com a disponibilidade de cada paciente, e a elaboração de um questionário gravado, cujo objetivo era colher a impressão pessoal do paciente com a nova terapia, completando assim a etapa. O cronograma foi estabelecido da seguinte forma: as práticas com o uso do Scratch aconteceram nos dias de quinta-feira e sextafeira, por cinco semanas consecutivas, sendo trabalhados dois pacientes por dia com uma duração de quarenta minutos cada sessão. Ao fim da aplicação foi aplicado o questionário, na forma de uma conversa informal aos pacientes, elaborado pelo Artesão, para concretizar o objetivo do referido.

Para a execução da terapia (fase 5) foi utilizado o editor de pintura (Figura 2) da plataforma virtual do Scratch, e sob orientação do artesão José Airton Rufino, profissional responsável por mediar a terapia, o paciente recebia as instruções de execução. O objetivo era criar desenhos livres de acordo com a vontade do usuário e, ao término, explicar subjetivamente o porquê daquele desenho (Questionário referido). Segundo o terapeuta 
artesão, essa técnica permite trabalhar o exercício da mente quando o usuário é solicitado a dar sentido a sua criação.



Figura 2: Editor de Pintura do Scratch. Fonte: Autoria própria, 2020

Todo o experimento foi acompanhado pelo artesão que mediou o processo do início ao fim e determinou até que ponto poderia ser trabalhado as necessidades dos usuários. As sessões eram realizadas individualmente e os resultados apresentados na sessão seguinte foram baseados nas observações do artesão juntamente com as impressões subjetivas dos usuários captadas por meio do questionário.

\section{Resultados e Discussões}

A finalidade desse estudo foi analisar o uso tecnológico como fator determinante para impulsionar as habilidades cognitivas dos pacientes psiquiátricos designados à terapia computacional pela Classificação Internacional de Doenças (CID 10). Na análise das variáreis investigadas, a coordenação motora se destacou como a habilidade primordial a ser desenvolvida pela necessidade de se ter o controle dos músculos na execução das terapias, e depois de adquirido algumas competências, foi possível notar mais facilidade no manuseio da máquina vertendo a aplicação positiva nas desenvolturas da criatividade dos pacientes, bem como na visão seletiva deles. A criatividade intelectual dos pacientes, inicialmente bloqueada pelo receio da nova aplicação, logo foi se libertando com a autoconfiança adquirida no decorrer do experimento emergindo um olhar mais crítico a cada passo desenvolvido no software, caracterizando a visão seletiva deles. Este trabalho, por sua vez, concentrou-se, especificamente, no aprimoramento destas habilidades por se tratarem de competências imprescindíveis no que tange às terapias que envolvem ferramentas computacionais, bem como outras atividades afins.

Numa análise pedagógica, o desenho livre além de ajudar na coordenação motora fina, desperta a criatividade proporcionando um alinhamento das limitações com a prática do desenho, podendo o profissional adaptar o instrumento utilizado nas próximas terapias, conforme se mostrou a experiência anterior. Atestando o fragmento supracitado, Sbardella (2018) afirma que "O pedagogo que atua nas oficinas do CAPS proporciona aulas dinâmicas, trabalhando com esses pacientes suas dificuldades e limitações, favorecendo a integridade e o cuidado com cada um deles, auxiliando-os através da leitura, da escrita, técnicas de pintura, jogos pedagógicos, recorte e colagem, brincadeiras relativas à educação". A expressão do eu interior promove o desenvolvimento de capacidades que tornam útil a existência da pessoa, tornando-se uma forma de construir 
conhecimentos, pois é uma atividade que envolve a inteligência, o pensamento, e a cognição; e a figura 3 apresenta uma espécie de jogo desenvolvido no Scratch, em nível já avançado, para se estimular as três variáveis simultaneamente.

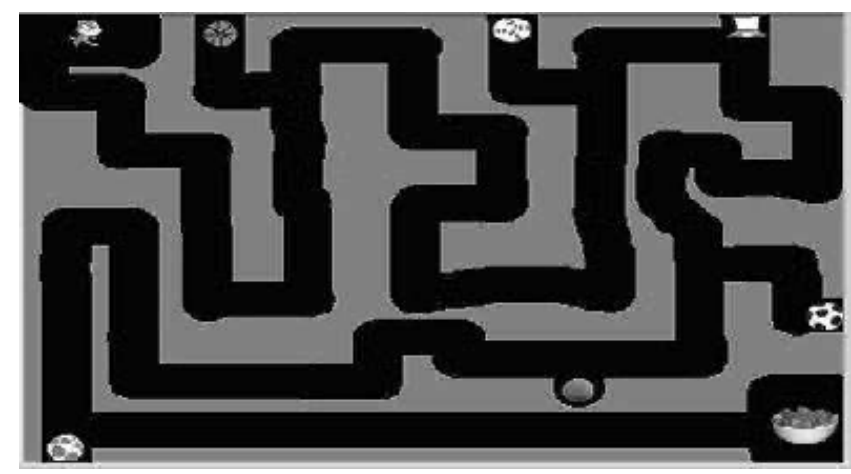

Figura 3: Jogo desenvolvido no Scratch. Fonte: Leal, 2019.

A execução da terapia ilustrada na figura 3 consistiu em aplicar comandos para o gato (Símbolo do Scratch) percorrer todo o labirinto, sem tocar as paredes, e durante o percurso, entrar nas ramificações para pegar os objetos que nelas estão antes de chegar ao objetivo final.

Após concluído a execução do experimento o artesão da instituição, José Airton Rufino, aferiu o que segue:

"As gravuras criadas pelos pacientes neste software (Scratch) emergiu positivamente nos seus quadros psíquicos, apontando seus estados de espíritos e inquietações; e que, ao colocarem suas emoções para fora, na tela, promoveram o bem estar fazendo se sentirem úteis, vistos, vivos e ainda em evolução, caracterizando assim a terapia."

Ao final, o Neuropsicopedagogo da Instituição, Adaljerry Ferreira de Sousa, também proferiu seu parecer sobre o experimento:

\begin{abstract}
"Com base em análises da utilização do aplicativo Scratch em atividades com intensivos no Centro de Atenção Psicossocial - CAPS, Inhuma (Piauí), percebeu-se que os objetivos do referido aplicativo aderem às propostas de atendimentos terapêuticos, buscando uma aproximação da utilidade prática com as necessidades de cada paciente. Com isto acredita-se que este tipo de terapia poderia amenizar episódios de ansiedade, pois utiliza ferramentas inovadoras como terapias complementares ao tratamento medicamentoso que os pacientes são submetidos".
\end{abstract}

Existem vários registros de autores que externam as características fundamentais no desenvolvimento cognitivo do processo de aprendizagem, sendo elas: atenção, memória, motivação e o público-alvo desta pesquisa, ou seja, pessoas com Deficiência Intelectual. E corroborando com a percepção pessoal do artesão descrita acima, Oliveira, A. (2017) afirma que:

A pintura e o artesanato são tão importantes que servem como recurso terapêutico, o que acarreta na ativação dos canais sensoriais durante sua prática. Isso melhora a equilibrar as emoções e libertar a imaginação e pensamentos.

\title{
4.1 Avaliação subjetiva do experimento
}

Ao final da experiência foi aplicado o questionário junto aos pacientes, ainda assistidos 
pelo artesão, que buscou avaliar a satisfação subjetiva deles na realização da tarefa, assim como as experiências vividas pelos mesmos durante as sessões. Os questionamentos do artesão eram voltados para a introdução da nova terapia e buscava interagir com a concepção individual de cada paciente sobre o uso da ferramenta, que numa escala de 0 a 10 teve uma média aproximada de 9,5 para o nível de aceitação avaliado pelos usuários como mostra o gráfico abaixo (Gráfico 1).

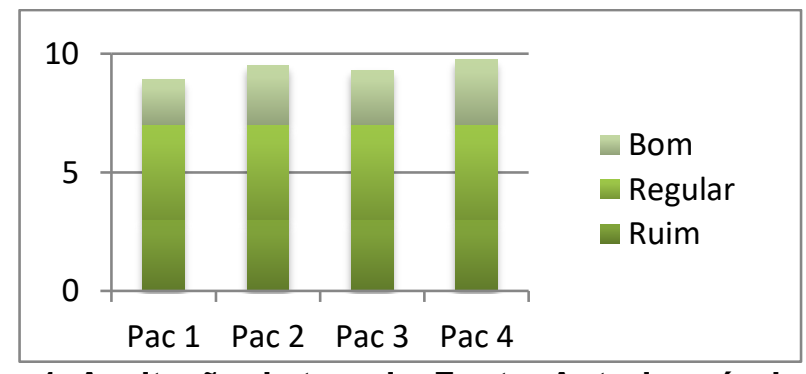

Gráfico 1. Aceitação da terapia. Fonte: Autoria própria, 2020

Nas atribuições que lhe compete e para observações particulares, o artesão promoveu um levantamento das desenvolturas dos pacientes frente as suas dificuldades ao iniciar o experimento e todo progresso sucedido foi documentado pelos autores na forma de um gráfico, com escala mínima 0 (zero) considerada sem dificuldade, escala média 2,5 considerada dificuldade regular e escala máxima 5 considerada dificuldade extrema nas desenvolturas da Coordenação Motora Fina (CMF), Criatividade Intelectual (CI) e Visão Seletiva (VS) (Gráfico 2). As informações colhidas nesse levantamento dignificaram um projeto social destinado ao órgão superior que rege as normas e condutas do CAPS, a Secretaria Municipal de Saúde. O objetivo desse projeto era integrar essa terapia computacional às demais já realizadas na Instituição, que se consumaria ao término do experimento caso o mesmo retornasse um feedback positivo no quadro de evolução dos pacientes.

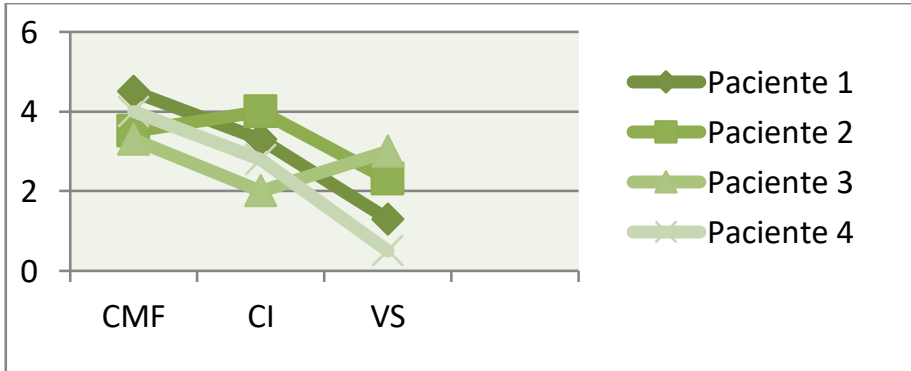

Gráfico 2. Fase inicial da terapia. Fonte: Autoria própria, 2020

Sobre o questionário que foi realizado, segue as impressões subjetivas dos pacientes captadas pelo artesão por meio de um bate-papo informal. A conversa não foi muito extensa devido às limitações conhecidas, então optou-se por não os pressioná-los sob risco de alteração em seus quadros psíquicos. Com isso, apenas dois pacientes deixaram suas contribuições ao falar sobre a aplicação do Scratch e revelaram:

"Esse joguinho é muito bom porque a gente desenha no computador. A gente fica
tão entretido que nem vê o tempo passar e depois Zé Airton (Artesão) vai imprimir
os desenhos para a gente levar para casa." (Paciente 1)
"É bom fazer desenho no computador. Já era para o CAPS ter exercício de
computação há muito tempo. Eu nunca tinha pegado em um computador, por isso 
que eu fiquei com um pouco de medo de quebrar alguma coisa, mas agora tem que ter por que é melhor desenhar no computador do que no papel". (Paciente 2)

Assim como na fase inicial da terapia, utilizou-se também um gráfico com as mesmas escalas para representar os dados de evolução dos pacientes, na visão do artesão, para sintetizar os resultados ao final da experiência (Gráfico 3).

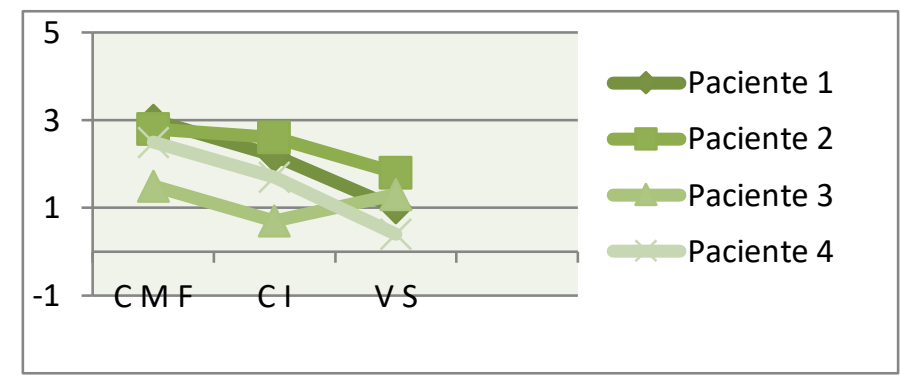

Gráfico 3. Fase final da terapia. Fonte: Autoria própria, 2020

Na concepção analítica do artesão, entre o gráfico 2 (Fase inicial) e o gráfico 3 (Fase final) está o período de evolução dos pacientes no uso do software superando os níveis de dificuldade (Tabela 2).

Tabela 2. Evolução dos pacientes com o uso da ferramenta.

\begin{tabular}{|l|c|c|c|c|c|c|c|c|}
\hline & \multicolumn{2}{|c|}{ Paciente 1 } & \multicolumn{2}{c|}{ Paciente 2 } & \multicolumn{2}{c|}{ Paciente 3 } & \multicolumn{2}{c|}{ Paciente 4 } \\
\hline $\begin{array}{l}\text { Período / } \\
\text { Cognições }\end{array}$ & Início & Fim & Início & Fim & Início & Fim & Início & Fim \\
\hline (CMF) & 4,5 & 3 & 3,5 & 2,8 & 3,3 & 1,5 & 4 & 2,5 \\
\hline$(\mathrm{CI})$ & 3,3 & 2,2 & 4 & 2,6 & 2 & 0,7 & 2,8 & 1,7 \\
\hline (VS) & 1,3 & 1 & 2,3 & 1,8 & 3 & 1,3 & 0,5 & 0,4 \\
\hline
\end{tabular}

Durante o experimento, a ferramenta atuou como auxílio estimulador no processo terapêutico ocupacional despertando curiosidade e medo simultaneamente, isso devido as peculiaridades do público alvo. Transtornos psíquicos aludem anseios de tristeza, ineficácia, inexistência, dentre outros tantos que justificam a sensação de medo externada por alguns pacientes no uso da ferramenta inovadora.

\section{Conclusão e Trabalhos Futuros}

Este trabalho apresentou um experimento com o uso de ferramenta computacional Scratch como parte das terapias ocupacionais do centro terapêutico de saúde mental da cidade de Inhuma (Piauí). E baseado na Tabela 2, onde apresenta a evolução de cada paciente durante o tempo de aplicação da terapia, pode-se notar o desenvolvimento das habilidades cognitivas tencionadas na pesquisa.

Contudo, mesmo diante dos desafios supracitados, os resultados percebidos de forma observacional e analítica, principalmente pelo Artesão José Airton Rufino, constataram que a aplicação do software foi positiva no que se refere à terapia, pois notadamente se percebeu motivação individual nos pacientes, bem como o despertar para o interesse em se estabelecer o contato contínuo com o software, expectativas criadas com a aplicação do experimento no âmbito das terapias artesanais, atingindo assim o objetivo de incluir e socializar digitalmente aqueles pacientes.

Diante do exposto, é preciso olhar o deficiente mental na perspectiva de sujeito inserido na era digital, e para isto, sugere-se como trabalhos futuros a implementação desta pesquisa com novas atribuições sob outras ferramentas que se assemelham ao 
IX Congresso Brasileiro de Informática na Educação (CBIE 2020)

Anais do XXVI Workshop de Informática na Escola (WIE 2020)

Scratch para integrar ainda mais pacientes, a exemplo daqueles que não puderam ser atendidos pelo Scratch.

\section{Referências}

Acioly, Y. (2009). Reforma psiquiátrica: Construção de outro lugar social para a loucura?. Paraná.

Babinski, C. (2005). Projeto de Atenção Psicossocial-CAPS. Prefeitura Municipal de Abelardo Luz/Secretaria de Saúde. Santa Catarina.

Farias, C.; Cruz, V.; Farias, J.; Braz, D.; Brito, B.; Carvalho, A.; (2019). Estimulando o pensamento Computacional: uma experiência com ScratchJr. In: XXV Workshop de Informática na Escola, Brasília. Anais do XXV Workshop de Informática na Escola (WIE 2019), 2019. p. 197-206.

Fortuna, T. R., Oliveira, M. R. (2011). Mapeamento das práticas comunicacionais radiofônicas como terapia psicossocial nos serviços de saúde mental no Brasil. RJ.

Fulford, H.; McSwiggan, L.; Kroll, T.; MacGillivray, S. (2019). Explorando o uso de tecnologias móveis de informação e comunicação por pessoas com transtornos do humor. In: International Journal of Mental Health Nursing. ed, junho de 2019.

Leal, L.; Aita, K.; Silva, A. (2019). Experiência com o uso da Ferramenta Scratch na Terapia dos Pacientes Psiquiátricos. In: XXV Workshop de Informática na Escola, Brasília. Anais do XXV Workshop de Informática na Escola (WIE 2019), 2019. p. 954-963.

Marinho, A.; Souza, G.; Rosa, J.; Morais; P.; (2017). O uso do Scratch na educação básica: Um relato de experiência vivenciada no PIBID. In: VI Congresso Brasileiro de Informática na Educação (CBIE 2017). Anais do XXIII Workshop de Informática na Escola (WIE 2017), 2017. P. 402 - 411.

Oliveira, A. (2017). O Artesanato e seus Benefícios. Disponível em: < https://artesanatonlineblog.wordpress.com/category/artesanatos/>. Minas Gerais.

Oliveira, C. (2016). PARADEP - Ferramenta de apoio ao diagnóstico da depressão baseada na lógica para consistente. São Paulo.

Santana et al. (2017). Scratch Jr - Brincando em Família: um relato de experiências sobre introdução a programação no ambiente escolar. In: VI Congresso Brasileiro de Informática na Educação (CBIE 2017). Anais do XXIII Workshop de Informática na Escola (WIE 2017).

Santana, S.; Oliveira, W. (2019). Desenvolvendo o Pensamento Computacional no Ensino Fundamental com o uso do Scratch. In: XXV Workshop de Informática na Escola, Brasília. Anais do XXV Workshop de Informática na Escola (WIE 2019), 2019. p. 158-167.

Sbardella, E. (2018). A importância do pedagogo no Centro de Atenção Psicossocial-caps 1 Reviver de Abelardo Luz / SC. Santa Catarina.

Zednik, H.; Takinami, O.; Silva, R.; Sales, S.; Araújo, S. (2019). Contribuições do Software Scratch para Aprendizagem de Crianças com Deficiência Intelectual In: XXV Workshop de Informática na Escola, Brasília. Anais do XXV Workshop de Informática na Escola (WIE 2019), 2019. p. 394-403. 